Int. J. Electrochem. Sci., 15 (2020) 6405 - 6424

\title{
Corrosion and Biocompatibility Behavior of the Micro-Arc Oxidized AZ31B Alloy in Simulated Body Fluid
}

\author{
Chun-Ying Lee $e^{1}$, Kun-Lin Chen ${ }^{1}$, Zhu-Min Xu', and Hung-Bin Lee $e^{3, *}$ \\ ${ }^{1}$ Graduate Institute of Manufacturing Technology, National Taipei University of Technology, \\ Taipei 10608, Taiwan \\ ${ }^{2}$ Bachelor Program for Design and Materials for Medical Equipment and Devices, Da-Yeh University, \\ Changhua 515, Taiwan \\ ${ }^{3}$ Department of Optoelectronics and Materials Technology, National Taiwan Ocean University, \\ Keelung 202, Taiwan \\ *E-mail: $\underline{\text { lhb6018@mail.ntou.edu.tw }}$
}

doi: $10.20964 / 2020.07 .68$

Received: 16 March 2020 / Accepted: 11 May 2020 / Published: 10 June 2020

The corrosion behavior of AZ31B magnesium alloy in simulated body fluid (SBF) was investigated in this study. In order to improve its corrosion resistance, a micro-arc oxidation (MAO) treatment was performed on the AZ31B specimen. Specimens subjected to different processing durations in the electrolyte containing silicate, sodium hydroxide and sodium citrate were prepared with pulsed direct current first. The then measured potentio-dynamic polarization curve of the specimen in SBF revealed that the one with 30-min treatment had the best corrosion resistance. After submersion of the MAO specimen in SBF for several days, the microstructural examination on the cross-section showed the infusion of SBF through the porous and cracked oxide and induced corrosion near the substrate. At the same time, a homogeneous layer of apatite appeared on the surface of the specimen in the original porous oxide layer. This apatite layer was confirmed by the measured $\mathrm{Ca} / \mathrm{P}$ molar ratio of $1.54-1.67$ through its thickness. Moreover, the cell toxicity of this AZ31B specimen was tested using mouse neuroma cells. The cultivation of the cell in cytotoxicity test showed good survival rate and the axon was grown on the division of the cells.

Keywords: AZ31B, micro-arc oxidation, simulated body fluid (SBF), corrosion, cytotoxicity

\section{$\underline{\text { FULL TEXT }}$}

(C) 2020 The Authors. Published by ESG (www.electrochemsci.org). This article is an open access article distributed under the terms and conditions of the Creative Commons Attribution license (http://creativecommons.org/licenses/by/4.0/). 